\title{
Migraine, headache, and mortality in women: a cohort study
}

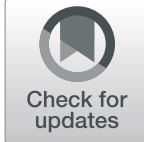

\author{
Jessica L. Rohmann ${ }^{*}$, Pamela M. Rist ${ }^{2}$, Julie E. Buring ${ }^{2}$ and Tobias Kurth ${ }^{1}$
}

\begin{abstract}
Background: Migraine carries a high global burden, disproportionately affects women, and has been implicated as a risk factor for cardiovascular disease. Migraine with aura has been consistently associated with increased risk of cardiovascular mortality. However, published evidence on relationships between migraine or non-migraine headache and all-cause mortality is inconclusive. Therefore, we aimed to estimate the effect of non-migraine headache and migraine as well as migraine subtypes on all-cause and cause-specific mortality in women.

Methods: In total, 27,844 Women's Health Study participants, aged 45 years or older at baseline, were followed up for a median of 22.7 years. We included participants who provided information on migraine (past history, migraine without aura, or migraine with aura) or headache status and a blood sample at study start. An endpoints committee of physicians evaluated reports of incident deaths and used medical records to confirm deaths due to cardiovascular, cancer, or female-specific cancer causes. We used multivariable Cox proportional hazards models to estimate the effect of migraine or headache status on both all-cause and cause-specific mortality.

Results: Compared to individuals without any headache, no differences in all-cause mortality for individuals suffering from non-migraine headache or any migraine were observed after adjustment for confounding $(H R=1.01,95 \% \mathrm{Cl}$, 0.93-1.10 and $H R=0.96,95 \% \mathrm{Cl}: 0.89-1.04)$. No differences were observed for the migraine subtypes and all-cause death. Women having the migraine with aura subtype had a higher mortality due to cardiovascular disease (adjusted $\mathrm{HR}=1.64,95 \% \mathrm{Cl}: 1.06-2.54)$. As an explanation for the lack of overall association with all-cause mortality, we observed slightly protective signals for any cancer and female-specific cancers in this group.
\end{abstract}

Conclusions: In this large prospective study of women, we found no association between non-migraine headache or migraine and all-cause mortality. Women suffering from migraine with aura had an increased risk of cardiovascular death. Future studies should investigate the reasons for the increased risk of cardiovascular mortality and evaluate whether changes in migraine patterns across the life course have differential effects on mortality.

Keywords: Migraine, Headache, Mortality, Women, Epidemiology

\section{Introduction}

Migraine is a common chronic, intermittent primary headache disorder affecting $15 \%$ to $18 \%$ of the general adult population, mainly affecting women [1]. According to the 2016 Global Burden of Disease data, migraine is one of the

\footnotetext{
* Correspondence: jessica.rohmann@charite.de

'Institute of Public Health, Charité - Universitätsmedizin Berlin, Chariteplatz 1, 10117 Berlin, Germany

Full list of author information is available at the end of the article
}

ten most disabling disorders and is ranked second globally for years of life lived with disability [2].

Migraine can be subdivided into migraine with aura and migraine without aura. The migraine aura is characterized by transient neurological symptoms (often lasting 5-60 min before the migraine pain), mostly affecting the visual field [3]. Individuals with migraine have a higher risk for multiple comorbid conditions, including cardiovascular disease [4-7], and some studies have linked this added risk specifically to the aura subtype [7-9].

(c) The Author(s). 2020 Open Access This article is licensed under a Creative Commons Attribution 4.0 International License, which permits use, sharing, adaptation, distribution and reproduction in any medium or format, as long as you give appropriate credit to the original author(s) and the source, provide a link to the Creative Commons licence, and indicate if changes were made. The images or other third party material in this article are included in the article's Creative Commons licence, unless indicated otherwise in a credit line to the material. If material is not included in the article's Creative Commons licence and your intended use is not permitted by statutory regulation or exceeds the permitted use, you will need to obtain permission directly from the copyright holder. To view a copy of this licence, visit http://creativecommons.org/licenses/by/4.0/ The Creative Commons Public Domain Dedication waiver (http://creativecommons.org/publicdomain/zero/1.0/) applies to the data made available in this article, unless otherwise stated in a credit line to the data. 
We have limited knowledge regarding the association of migraine on all-cause mortality. No overall association was found in a 2011 meta-analysis of five pooled studies [10]. More recently, no association with all-cause mortality was observed in two large cohort studies [11, 12]. A recent Taiwanese study found that people with migraine had lower all-cause mortality than individuals without migraine, though this study did only captured in-hospital mortality and many important sources of confounding may have been omitted by the variable selection process [13].

Given the increased risk for cardiovascular mortality but lack of increased risk on all-cause mortality, we are led to believe there may be differential effects of having migraine in general and of migraine aura subtypes on disease-specific mortality. Specifically, perhaps individuals with active migraine have lower risk for other cause-specific death events, particularly female-specific cancers, as these cancers and migraine are linkable to hormone levels. For these reasons, in the present study, we aimed to estimate the effect of having migraine or non-migraine headache, as well as specific migraine subtypes on all-cause and cause-specific mortality in a large population-based cohort study of women.

\section{Methods}

\section{Study population}

The Women's Health Study (WHS) began as a large, randomized, placebo-controlled trial $(N=39,876)$ designed to test the effects of aspirin and vitamin $\mathrm{E}$ on the primary prevention of cardiovascular disease (CVD) and cancer. The design, methods, and main results of the trial have been described in detail elsewhere [14, 15]. Briefly, at baseline (1992-1995), 39,876 US female health professionals aged 45 years or older without a history of cardiovascular disease, cancer, or other major illnesses were randomized to receive low-dose aspirin (versus placebo) or vitamin $\mathrm{E}$ (versus placebo) in a 2-by-2 factorial design. After the trial concluded in 2004, the study continued as a cohort design, and participants continued to be followed on an observational basis.

Women were sent follow-up questionnaires requesting information about demographics, lifestyle, and health information twice during the first year and annually thereafter. Written informed consent was obtained from all participants, and the WHS was approved by the Institutional Review Board at Brigham and Women's Hospital (clinicaltrials.gov identifier: NCT00000479).

\section{Inclusion and exclusion criteria}

At baseline, a total of 28,345 women provided venous blood samples, of which 27,937 could be assayed for cholesterol levels. Of this group, we excluded participants with missing information on the exposure (migraine or headache status at baseline, $N=79$ ). We additionally excluded participants who died after randomization but before the 6-month questionnaire $(N=9)$ or for whom no questionnaire was available $(N=5)$, leaving us with 27,844 women included in the present study.

\section{Assessment of exposure: migraine and non-migraine headache}

The main exposure variable for headache was classified into three categories: (1) no history of migraine or headache, (2) non-migraine headache, or (3) any migraine. Migraine and headache were classified as previously described [16]. Briefly, on the baseline questionnaire, participants were asked whether they had ever experienced migraine headaches and whether they had had migraine headaches in the year prior to baseline. Women responding positively to either of these questions were classified as having "any migraine." Information about non-migraine headache was asked on the questionnaire disseminated 6 months after baseline, since there was no question about general, non-migraine headache on the baseline questionnaire. We classified participants as having "non-migraine headache" if they reported headache on the 6-month questionnaire but reported no migraine history on the baseline questionnaire. Participants reporting neither were classified as having "no history of migraine or headache."

To further classify the main exposure variable into migraine subtypes, we used additional information, which was obtained on the baseline questionnaires. For this more detailed secondary categorization, five mutually exclusive headache exposure groups were created: no headache history, non-migraine headache, migraine with aura, migraine without aura, and past history of migraine. In an effort to avoid recall bias, we asked only those participants who reported having migraine within the last year about experiencing aura or any other indication that a migraine attack was coming. We classified women who reported such phenomena as having "migraine with aura", if not, participants reporting active migraine within the last year were classified as having "migraine without aura." Women who reported a past history of migraine but no active migraine in the last year prior to baseline were classified as having "past history of migraine." A previous study in the WHS demonstrated good agreement (more than $87 \%$ ) between selfreported migraine and self-reported symptoms of the International Classification of Headache Disorders II criteria [17].

\section{Ascertainment of outcomes: all-cause and disease-specific mortality}

For the primary outcome, all reported deaths of all causes were confirmed using information from autopsy reports, death certificates, medical records, and information 
obtained from next of kin or family members. Diseasespecific causes of death due to cardiovascular diseases, any cancers, or female-specific cancers, the secondary outcomes, were confirmed by an Endpoints Committee of physicians using medical records. Female-specific cancers included breast cancer, cervical cancer, endometrial cancer, ovarian cancer, and uterine cancer.

\section{Statistical analysis}

In the present study, we computed person-time from the time of dissemination of the 6-month questionnaire (6 months after initial randomization) to the time of death, loss-to-follow-up, or the administrative censorship date of December 31, 2017.

Cox proportional hazards regression models were used to estimate hazard ratios (HRs) and corresponding 95\% confidence intervals $(95 \% \mathrm{CI})$ for the effects of headache status on all-cause mortality using the group of participants with no history of migraine or headache as the reference category. HRs and 95\% CIs for the secondary outcomes of cardiovascular mortality, any cancer mortality, and female-specific cancer mortality were also estimated. No violations of the proportional hazard assumption were observed upon visual inspection of the survival distribution curves for the exposure categories plotted over survival time. As a sensitivity analysis for the secondary outcomes, Fine-Gray subdistribution hazard models were used to account for competing risks. For each model, any deaths due to causes other than the cause of interest were treated as competing events.

We report results from models adjusted for age at randomization as well as multivariable-adjusted models. In our multivariable-adjusted models, we included the following variables measured at baseline identified a priori based on prior knowledge to address potential confounding: age (in years) at randomization, body mass index (BMI) categories based on World Health Organization cut-offs (underweight/normal: $<25$, overweight: $25-30$, or obese: $\geq 30 \mathrm{~kg} / \mathrm{m}^{2}$ ), total cholesterol in Adult Treatment Panel III [18] categories $(<200,200-$ 239.9 , or $\geq 240 \mathrm{mg} / \mathrm{dL}$ ), smoking status (never, past or current), alcohol consumption (rarely/never, 1-3 drinks per month, 1-6 drinks per week, or $\geq 1$ drink per day), physical activity (rarely/never, $<1$ time per week, 1 to 3 times per week, $\geq 4$ times per week), history of diabetes, history of hypertension (self-reported history of hypertension, systolic blood pressure $>140$, diastolic blood pressure $>90 \mathrm{mmHg}$ or prescription antihypertensive treatment), family history of myocardial infarction in parent aged < 60 years, and family history of cancer (composite variable of colorectal cancer in parents or siblings at any age, ovarian cancer in mother or sister at any age, or breast cancer in mother or sister aged $<60$ years).
Very few women were missing covariate information. All covariates included in the multivariable models had 24 or less missing values except for family history of myocardial infarction $(N=460)$, in which case we created a separate category for women missing this information. For the family history of cancer variable, 858 women were missing information on family history of breast cancer and were imputed to no family history of cancer. For the remaining categories with small numbers of missing values, we imputed the most common or reasonable value. For BMI, we imputed the mean BMI value before categorizing $(N=23)$. For categorical covariates, we imputed the reference category (alcohol consumption, $N=6$; physical activity, $N=10$; history of diabetes, $N=15$; history of hypertension, $N=7$ ) or the past user category (smoking, $N=24$ ).

We performed an additional post-hoc exploratory analysis to assess associations whether mortality hazards were elevated among those with more frequent migraine attacks. For this analysis, we categorized the exposure into six groups: (1) no history of migraine or headache, (2) non-migraine headache only, (3) past history of migraine, (4) active migraine less than once per month in the year before baseline, (5) active migraine about once per month, and (6) active migraine weekly or daily.

In a further post-hoc sensitivity analysis to address potential residual confounding by socioeconomic status (SES), we created a 10-point SES index based on available income and education information, in accordance with previously published work [19]. We re-ran the previously described multivariable models for the primary outcome, all-cause mortality, with additional adjustment for the SES index using the missing indicator method.

We used SAS statistical software (version 9.4) for all analyses.

\section{Results}

Of the 27,844 participating women in this study, 5128 reported any migraine (1435 migraine with aura, 2175 migraine without aura, and 1518 past history of migraine) and 4025 non-migraine headache at baseline. Women who reported having any migraine at baseline were generally younger, less likely to be current smokers, consumed less alcohol and less frequently reported having diabetes or hypertension (Table 1). We present stratified participant characteristics by all headache and migraine subtypes according to the secondary classification in Additional file 1: Supplementary Table 1.

During a median of 22.7 years of follow-up (range: 0.02 to 24.1 years), a total of 5012 deaths were confirmed, of which 386 were due to cardiovascular disease and 1224 were due to cancer (of these, 342 femalespecific cancer). 
Table 1 Baseline characteristics according to migraine or headache status $(N=27,844)$

\begin{tabular}{|c|c|c|c|}
\hline \multirow[t]{3}{*}{ Characteristics at baseline } & \multicolumn{3}{|c|}{ Migraine or headache status } \\
\hline & No history & $\begin{array}{l}\text { Non-migraine } \\
\text { headache }\end{array}$ & $\begin{array}{l}\text { Any } \\
\text { migraine }\end{array}$ \\
\hline & $N=18,691$ & $N=4025$ & $N=5128$ \\
\hline Age, mean (SD), years & $55.2(7.3)$ & $53.5(6.4)$ & $53.6(6.4)$ \\
\hline $\begin{array}{l}\text { Body mass index, mean } \\
\text { (SD), } \mathrm{kg} / \mathrm{m}^{2}\end{array}$ & $25.8(4.9)$ & $26.2(5.2)$ & $26.1(5.1)$ \\
\hline $\begin{array}{l}\text { Total cholesterol, median } \\
\text { (IQR), mg/dL }\end{array}$ & $\begin{array}{l}208 \\
(184-235)\end{array}$ & $\begin{array}{l}207 \\
(183-235)\end{array}$ & $\begin{array}{l}209 \\
(184-236)\end{array}$ \\
\hline \multicolumn{4}{|l|}{ Smoking status, \% } \\
\hline Never & 50.9 & 52.7 & 53.8 \\
\hline Past & 37.3 & 35.8 & 35.0 \\
\hline Current & 11.8 & 11.4 & 11.1 \\
\hline \multicolumn{4}{|l|}{ Alcohol consumption, \% } \\
\hline Rarely/never & 42.7 & 47.2 & 47.1 \\
\hline 1-3 drinks/month & 12.9 & 13.6 & 14.4 \\
\hline 1-6 drinks/week & 32.9 & 31.2 & 30.3 \\
\hline$\geq 1$ drink per day & 11.4 & 8.1 & 8.2 \\
\hline \multicolumn{4}{|l|}{ Vigorous physical activity, \% } \\
\hline Rarely/never & 37.2 & 36.4 & 38.3 \\
\hline$<1$ time/week & 18.8 & 20.8 & 21.5 \\
\hline 1-3 times/week & 31.9 & 33.5 & 30.0 \\
\hline$\geq 4$ times/week & 12.1 & 9.2 & 10.3 \\
\hline Diabetes, \% & 2.4 & 3.3 & 2.0 \\
\hline History of hypertension, $\%$ & 24.8 & 25.3 & 26.2 \\
\hline \multicolumn{4}{|l|}{ Family history of:, \% } \\
\hline Myocardial infarction ${ }^{a}$ & 13.6 & 15.4 & 15.3 \\
\hline Colorectal cancer $^{\mathrm{b}}$ & 10.7 & 9.8 & 9.6 \\
\hline Ovarian cancer $^{c}$ & 2.8 & 2.8 & 3.3 \\
\hline Breast cancer ${ }^{d}$ & 6.3 & 5.8 & 5.9 \\
\hline
\end{tabular}

Numbers may not add up to $100 \%$ because of rounding or missing data. All variables were measured at baseline. Medical history information was self-reported Abbreviations: SD Standard deviation, IQR Interquartile range

${ }^{a}$ in parent aged less than 60 years

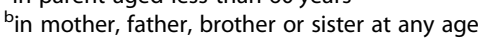

in mother or sister at any age

$d_{\text {in }}$ mother or sister aged less than 60 years

In Table 2, we report the age- and multivariableadjusted model results for the associations between headache or migraine status and all-cause and causespecific mortality. In the adjusted models, the estimated HRs and corresponding 95\% CIs for all-cause mortality were $1.01(0.93-1.10)$ for the "non-migraine headache" group and $0.96(0.89-1.04)$ for the "any migraine" group compared to the "no history" reference group, illustrating a robustly null relationship.

In secondary analyses, we investigated the association between migraine and cause-specific mortality from any cancer, cardiovascular disease, or female-specific cancers. Among those with non-migraine headache, no meaningful increase in mortality rate was observed for cardiovascular mortality $\left(\mathrm{HR}_{\mathrm{adj}}=0.99,0.72-1.36\right)$, any cancer death $\left(\mathrm{HR}_{\mathrm{adj}}=1.02,0.86-1.21\right)$ or female-specific cancer mortality $\left(\mathrm{HR}_{\mathrm{adj}}=0.87,0.62-1.21\right)$. No relationship was observed for the "any migraine" group with the outcomes cardiovascular mortality $\left(\mathrm{HR}_{\mathrm{adj}}=1.07,0.81-1.42\right)$, any cancer death $\left(\mathrm{HR}_{\mathrm{adj}}=0.98,0.84-1.15\right)$, or femalespecific cancer mortality $\left(\mathrm{HR}_{\mathrm{adj}}=0.88,0.65-1.19\right)$. We used the Fine-Gray subdistribution hazard models to account for competing risks and obtained similar results (Additional file 1: Supplementary Table 2).

For the more detailed exposure categorization including the migraine subtypes, the HRs (95\% CIs) for the primary outcome of all-cause mortality ranged from 0.91 $(0.80-1.03)$ for the group "migraine without aura" to 
Table 2 Age- and multivariable-adjusted hazard ratios for all-cause and disease-specific mortality according to migraine or headache status $(N=27,844)$

\begin{tabular}{|c|c|c|c|}
\hline \multirow[t]{2}{*}{ Migraine or headache status: } & No history, $(N=18,691)$ & Non-migraine headache, $(N=4025)$ & Any migraine, $(N=5128)$ \\
\hline & HR -ref- & HR $(95 \%$ Cl) & HR $(95 \% \mathrm{Cl})$ \\
\hline All-cause death, $N$ & 3614 & 641 & 757 \\
\hline Age-adjusted $^{a}$ & 1 (ref) & $1.04(0.96-1.14)$ & $0.95(0.87-1.02)$ \\
\hline Multivariable-adjusted $^{\mathrm{b}}$ & 1 (ref) & $1.01(0.93-1.10)$ & $0.96(0.89-1.04)$ \\
\hline Cardiovascular death, $N$ & 281 & 46 & 59 \\
\hline Age-adjusted $^{a}$ & 1 (ref) & $1.08(0.79-1.48)$ & $1.05(0.79-1.40)$ \\
\hline Multivariable-adjusted $^{\mathrm{b}}$ & 1 (ref) & $0.99(0.72-1.36)$ & $1.07(0.81-1.42)$ \\
\hline Cancer death, $N$ & 861 & 164 & 199 \\
\hline Age-adjusted $^{a}$ & 1 (ref) & $1.01(0.86-1.20)$ & $0.96(0.82-1.12)$ \\
\hline Multivariable-adjusted $^{\mathrm{b}}$ & 1 (ref) & $1.02(0.86-1.21)$ & $0.98(0.84-1.15)$ \\
\hline Female-specific cancer death ${ }^{c}, N$ & 248 & 41 & 53 \\
\hline Age-adjusted $^{a}$ & 1 (ref) & $0.85(0.61-1.19)$ & $0.86(0.64-1.16)$ \\
\hline Multivariable-adjusted $^{\mathrm{b}}$ & 1 (ref) & $0.87(0.62-1.21)$ & $0.88(0.65-1.19)$ \\
\hline
\end{tabular}

Abbreviations: HR Hazard ratio, Cl Confidence interval, ref, reference category

${ }^{\text {a }}$ Adjusted for age at baseline

${ }^{\prime}$ Adjusted for the following variables measured at baseline: age, BMl, total cholesterol, smoking, alcohol use, physical activity, diabetes, hypertension, family history of myocardial infarction, and family history of cancer (categorizations described in detail in the Methods)

cIncludes breast cancer, cervical cancer, endometrial cancer, ovarian cancer, and uterine cancer

$1.01(0.93-1.10)$ for the "non-migraine headache" group in the multivariable-adjusted models with "no history" as the reference category (Table 3).

In the cause-specific mortality analyses (Table 3), having migraine with aura resulted in a significantly increased hazard for cardiovascular mortality compared to the reference group of women without any headache or migraine (HR $=1.64,95 \%$ CI: $1.06-2.54)$. No other headache status group had significant effects on cardiovascular death. We observed slightly protective effects of having migraine with aura on any cancer and femalespecific cancers $(\mathrm{HR}=0.89,95 \% \mathrm{CI} 0.67-1.19$ and $\mathrm{HR}=$

Table 3 Age- and multivariable-adjusted hazard ratios for all-cause and disease-specific mortality according to migraine subtypes or non-migraine headache status $(N=27,844)$

\begin{tabular}{|c|c|c|c|c|c|}
\hline \multirow[t]{2}{*}{$\begin{array}{l}\text { Migraine or headache } \\
\text { status: }\end{array}$} & $\begin{array}{l}\text { No history, } \\
(N=18,691)\end{array}$ & $\begin{array}{l}\text { Non-migraine headache, } \\
(N=4025)\end{array}$ & $\begin{array}{l}\text { Migraine with aura, } \\
(N=1435)\end{array}$ & $\begin{array}{l}\text { Migraine without aura, } \\
(N=2175)\end{array}$ & $\begin{array}{l}\text { Past history of migraine, } \\
(N=1518)\end{array}$ \\
\hline & HR -ref- & HR $(95 \% \mathrm{Cl})$ & HR $(95 \% \mathrm{Cl})$ & HR $(95 \%$ Cl) & HR $(95 \% \mathrm{Cl})$ \\
\hline All-cause death, $N$ & 3614 & 641 & 198 & 253 & 306 \\
\hline Age-adjusted $^{\mathrm{a}}$ & 1 (ref) & $1.04(0.96-1.13)$ & $0.96(0.83-1.11)$ & $0.86(0.76-0.98)$ & $1.02(0.91-1.15)$ \\
\hline MV-adjusted ${ }^{\mathrm{b}}$ & 1 (ref) & $1.01(0.93-1.10)$ & $0.99(0.85-1.14)$ & $0.91(0.80-1.03)$ & $1.00(0.88-1.12)$ \\
\hline Cardiovascular death, $N$ & 281 & 46 & 22 & 12 & 25 \\
\hline Age-adjusted $^{a}$ & 1 (ref) & $1.08(0.79-1.47)$ & $1.55(1.00-2.39)$ & $0.64(0.36-1.14)$ & $1.08(0.72-1.63)$ \\
\hline MV-adjusted ${ }^{b}$ & 1 (ref) & $0.99(0.72-1.35)$ & $1.64(1.06-2.54)$ & $0.68(0.38-1.22)$ & $1.03(0.68-1.55)$ \\
\hline Cancer death, $N$ & 861 & 164 & 48 & 85 & 66 \\
\hline Age-adjusted $^{a}$ & 1 (ref) & $1.01(0.86-1.20)$ & $0.86(0.64-1.15)$ & $1.04(0.83-1.30)$ & $0.94(0.73-1.20)$ \\
\hline MV-adjusted ${ }^{\mathrm{b}}$ & 1 (ref) & $1.02(0.86-1.21)$ & $0.89(0.67-1.19)$ & $1.09(0.87-1.37)$ & $0.93(0.72-1.19)$ \\
\hline $\begin{array}{l}\text { Female-specific cancer } \\
\text { death, } N\end{array}$ & 248 & 41 & 12 & 26 & 15 \\
\hline Age-adjusted $^{a}$ & 1 (ref) & $0.86(0.61-1.19)$ & $0.72(0.40-1.29)$ & $1.05(0.70-1.58)$ & $0.74(0.44-1.25)$ \\
\hline MV-adjusted ${ }^{b}$ & 1 (ref) & $0.87(0.62-1.21)$ & $0.74(0.41-1.32)$ & $1.08(0.72-1.62)$ & $0.75(0.45-1.27)$ \\
\hline
\end{tabular}

Abbreviations: $H R$ Hazard ratio, $\mathrm{Cl}$ Confidence interval, ref, reference category; MV-adjusted, multivariable-adjusted

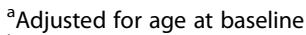

${ }^{\mathrm{b}}$ Adjusted for the following variables measured at baseline: age, BMI, total cholesterol, smoking, alcohol use, physical activity, diabetes, hypertension, family history of myocardial infarction, and family history of cancer

'Includes breast cancer, cervical cancer, endometrial cancer, ovarian cancer, and uterine cancer 
0.74, 95\% CI: 0.41-1.32), which likely explains, at least in part, the lack of a higher all-cause mortality risk in this group. For the detailed migraine subtype classification, the Fine-Gray subdistribution hazard models yielded similar results (Additional file 1: Supplementary Table 3).

We observed similar results for the complete case analysis as we did for our main analysis (results not shown). In the post-hoc exploratory analysis, we did not observe an association between increasing migraine frequency and increased risk of mortality (Table 4).

In the post-hoc sensitivity analysis to address potential residual confounding by socioeconomic status, additional adjustment for SES-index yielded very similar point estimates to the original multivariable-adjusted models. For the main exposure categorization, the estimated HRs and corresponding 95\% CIs for all-cause mortality were $1.01(0.92-1.09)$ for the "non-migraine headache" group and $0.95(0.88-1.03)$ for the "any migraine" group compared to the "no history" reference group. For the detailed secondary categorization including migraine subtypes, the HRs (95\% CIs) for the primary outcome of all-cause mortality were 1.01 (0.921.09 ) for the "non-migraine headache" group, 0.98 $(0.85-1.13)$ for the "migraine with aura" group, 0.90 $(0.79-1.03)$ for the group "migraine without aura", and $0.98(0.87-1.10)$ for the "past history of migraine" group.

\section{Discussion}

In this large, prospective cohort of women, we found no association between non-migraine headache or any migraine at baseline with all-cause mortality during followup. Furthermore, having migraine with aura, migraine without aura, or a past history of migraine were not found to be associated with all-cause death. This lack of association was apparent across all migraine frequency groups. Women with migraine with aura had increased hazard for cardiovascular disease-specific mortality compared to those with no history of headache. There was a suggestion that women with migraine with aura had a lower risk of cancer mortality, which was most evident for female-specific cancer mortality.

\section{Comparison with other studies}

Migraine and non-migraine headache have not been consistently linked with an increased risk of all-cause mortality [10-12]. Some studies even suggested a decreased risk [20]. Migraine, particularly migraine with aura, has been linked with increased risk of cardiovascular disease in prior reports from several individual studies $[5,6,8,9,21]$ and meta-analyses $[4,7]$.

Links between migraine and cancer have been assessed in a few studies; these are of interest due to proposed mechanisms of hormonal involvement for both migraine and cancer, particularly for breast cancer [20, 22-25], and ovarian cancer [26]. However, none of these studies evaluated cancer-specific death as an outcome. To the best of our knowledge, no other study has aimed to estimate the effect of migraine on cancer-specific mortality.

Potential biological mechanisms that increase cardiovascular mortality among women with migraine with aura are currently unknown. Potential mechanisms that have been proposed for the increased risk of cardiovascular disease include endovascular dysfunctions, inflammatory processes [27], genetic susceptibility [28, 29], and mechanisms leading to both migraine with aura and cardiovascular disease [3032]. Potential mechanisms linking migraine and cancer have been mainly proposed via hormone levels [20]. However, as there is a lack of robust evidence linking migraine and cancer, further speculative discussion about such a potential link is currently not warranted.

\section{Strengths and limitations}

Strengths of our study include the large number of women with migraine or non-migraine headache, long follow-up period, homogeneous composition of the cohort, which may reduce confounding of variables related to access to medical care, confirmed causes of death after medical record review or existing death certificate information, information on a number of potential confounding factors, and sensitivity analyses taking potential competing risk of death by other causes into account.

Several limitations should also be considered when interpreting our results. First, information on migraine, migraine characteristics, non-migraine headache, and included

Table 4 Age- and multivariable-adjusted hazard ratios for all-cause mortality according to migraine frequency $(N=27,844)$

\begin{tabular}{|c|c|c|c|c|c|c|}
\hline \multirow[t]{2}{*}{$\begin{array}{l}\text { Migraine or } \\
\text { headache } \\
\text { status: }\end{array}$} & $\begin{array}{l}\text { No migraine } \\
(\boldsymbol{N}=18,691)\end{array}$ & $\begin{array}{l}\text { Non-migraine } \\
\text { headache } \\
(\boldsymbol{N}=4025)\end{array}$ & $\begin{array}{l}\text { Past history of } \\
\text { migraine } \\
(\boldsymbol{N}=1518)\end{array}$ & $\begin{array}{l}\text { Active Migraine } \\
<1 / \text { month } \\
(\boldsymbol{N}=2727)\end{array}$ & $\begin{array}{l}\text { Active migraine } \\
\text { at least monthly } \\
(\boldsymbol{N}=703)\end{array}$ & $\begin{array}{l}\text { Active migraine } \\
\text { weekly or daily } \\
(\boldsymbol{N}=180)\end{array}$ \\
\hline & HR -ref- & HR (95\% Cl) & HR $(95 \%$ Cl) & HR $(95 \%$ Cl) & HR $(95 \%$ Cl) & HR (95\% Cl) \\
\hline All-cause death, $N$ & 3614 & 641 & 306 & 356 & 73 & 22 \\
\hline Age-adjusted $^{a}$ & 1 (ref) & $1.04(0.96-1.13)$ & $1.02(0.91-1.15)$ & $0.91(0.82-1.02)$ & $0.85(0.68-1.08)$ & $0.87(0.58-1.33)$ \\
\hline Multivariable-adjusted ${ }^{\text {b }}$ & 1 (ref) & $1.01(0.93-1.10)$ & $1.00(0.89-1.12)$ & $0.94(0.84-1.05)$ & $0.94(0.74-1.19)$ & $0.92(0.61-1.40)$ \\
\hline
\end{tabular}

Abbreviations: $H R$ Hazard ratio, $\mathrm{Cl}$ Confidence interval, ref., reference category

${ }^{\text {a }}$ Adjusted for age at baseline

${ }^{b}$ Adjusted for the following variables measured at baseline: age, BMI, total cholesterol, smoking, alcohol use, physical activity, diabetes, hypertension, family

history of myocardial infarction, and family history of cancer 
covariates were self-reported, and misclassification is possible. We cannot absolutely rule out that some of the participants classified as having migraine with aura actually experienced other events such as transient ischemic attacks, which were misdiagnosed by healthcare practitioners or by the individual participant themselves, if they did not seek medical care. However, given the usual age of migraine onset compared to other vascular events with some symptomatic overlap, we believe that this would be a rare scenario in our cohort.

Second, participating women were all healthcare professionals, and results may not be fully generalizable to other female populations and should not be extrapolated to men.

Third, although we are not aware of any major sources of confounding for which we lacked information, we cannot rule out that certain comorbid conditions present at baseline that were not assessed may have impacted risk for migraine status at baseline as well as long-term risk for mortality, introducing some unmeasured confounding. An additional post-hoc sensitivity analysis additionally adjusting our multivariable models for SES index yielded minimal change in the observed effect estimates, suggesting that there was little residual confounding due to SES as measured by the index.

Lastly, we unfortunately had no detailed information on individual trajectories of migraine and non-migraine headache during follow-up and thus could not estimate the influence of patterns and changes in migraine and non-migraine headache over time and risk of mortality.

\section{Conclusions}

In this large prospective study of women, we found no association between non-migraine headache or migraine (regardless of migraine aura status) and all-cause mortality. Women suffering from migraine with aura were found to have an increased hazard for cardiovascular death compared to women with no history of migraine or headache. Future studies should investigate the underlying reasons for the observed increased risk of cardiovascular mortality for this subtype and evaluate whether changes in migraine patterns across the lifecourse may have differential effects on mortality.

\section{Supplementary information}

Supplementary information accompanies this paper at https://doi.org/10 1186/s10194-020-01091-9.

Additional file 1: Supplementary Table S1. Baseline characteristics according to migraine subtypes or non-migraine headache status ( $N=$ 27,844). Supplementary Table S2. Fine-Gray subdistribution age- and multivariable-adjusted hazard ratios for cause-specific mortality account ing for competing risks according to migraine or headache status ( $N=$ 27,844). Supplementary Table S3. Fine-Gray subdistribution age- and multivariable-adjusted hazard ratios for cause-specific mortality accounting for competing risks according to migraine subtypes or nonmigraine headache status $(N=27,844)$.

\section{Abbreviations}

BMI: Body Mass Index; Cl: Confidence interval; CVD: Cardiovascular disease; HR: Hazard ratio; SES: Socioeconomic status; WHS: Women's Health Study

\section{Acknowledgements}

We acknowledge support from the German Research Foundation (DFG) and the Open Access Publication Fund of the Charité - Universitätsmedizin Berlin

\section{Authors' contributions}

PMR, JEB, and TK were responsible for project conception and design. PMR and JEB were involved in data collection and management. JEB obtained funding and TK supervised the project. JLR and PMR performed the analyses. $J L R, P M R$ and TK interpreted the results. JLR drafted the first manuscript draft. All authors provided critical revisions and approved the final version.

\section{Funding}

The Women's Health Study is funded by National Institutes of Health grants: CA047988, HL043851, HL080467, HL099355, and UM1 CA182913. JLR's research position is funded by a grant from the Else-Kröner-Fresenius-Foundation, Germany (GSO/EKFS 17, to TK); PMR is funded by K01 HL128791. The funders played no role in the design and conduct of the study; collection, management, analysis, and interpretation of the data; and preparation, review, or approval of the manuscript; and decision to submit the manuscript for publication.

\section{Availability of data and materials}

The data are not publicly available because they contain information that could compromise research participant privacy/consent.

\section{Ethics approval and consent to participate}

Written informed consent was obtained from all participants, and the Women's Health Study was approved by the Institutional Review Board at Brigham and Women's Hospital (clinicaltrials.gov identifier: NCT00000479).

\section{Consent for publication}

Not applicable.

\section{Competing interests}

$J \mathrm{~L}, \mathrm{PMR}$, and JEB report no disclosures. TK reports having received honoraria from Novartis and Daiichi-Sankyo for lectures on neuroepidemiology and research methods, from Lilly, Newsenselab, and Total for providing methodological advice, and from The BMJ for editorial services. He provided methodological advice for Amgen and CoLucid, for which the Charité - Universitätsmedizin Berlin received unrestricted funds.

\section{Author details}

${ }^{1}$ Institute of Public Health, Charité - Universitätsmedizin Berlin, Chariteplatz 1 , 10117 Berlin, Germany. 'Division of Preventive Medicine, Department of Medicine, Brigham and Women's Hospital, Harvard Medical School, Boston, MA, USA.

Received: 28 November 2019 Accepted: 2 March 2020

Published online: 17 March 2020

\section{References}

1. Burch RC, Loder S, Loder E, Smitherman TA (2015) The prevalence and burden of migraine and severe headache in the United States: updated statistics from government health surveillance studies. Headache 55(1):2134

2. GBD 2016 Neurology Collaborators (2019) Global, regional, and national burden of neurological disorders, 1990-2016: a systematic analysis for the Global Burden of Disease Study 2016. Lancet Neurol 18(5):459-480

3. Arnold M (2018) Headache Classification Committee of the International Headache Society (IHS) The International Classification of Headache Disorders, 3rd edition. Cephalalgia 38(1):1-211 
4. Schürks M, Rist PM, Bigal ME, Buring JE, Lipton RB, Kurth T (2009) Migraine and cardiovascular disease: systematic review and meta-analysis. BMJ 339: b3914

5. Kurth T, Winter AC, Eliassen AH et al (2016) Migraine and risk of cardiovascular disease in women: prospective cohort study. BMJ 353:i2610

6. Adelborg K, Szépligeti SK, Holland-Bill L et al (2018) Migraine and risk of cardiovascular diseases: Danish population based matched cohort study. BMJ 360:k96

7. Mahmoud AN, Mentias A, Elgendy AY et al (2018) Migraine and the risk of cardiovascular and cerebrovascular events: a meta-analysis of 16 cohort studies including 1152407 subjects. BMJ Open 8(3):e020498

8. Kurth T, Gaziano JM, Cook NR, Logroscino G, Diener H-C, Buring JE (2006) Migraine and risk of cardiovascular disease in women. JAMA 296(3):283-291

9. Gudmundsson LS, Scher Al, Aspelund T et al (2010) Migraine with aura and risk of cardiovascular and all cause mortality in men and women: prospective cohort study. BMJ 341:C3966

10. Schürks M, Rist PM, Shapiro RE, Kurth T (2011) Migraine and mortality: a systematic review and meta-analysis. Cephalalgia 31(12):1301-1314

11. Åsberg AN, Stovner LJ, Zwart J-A, Winsvold BS, Heuch I, Hagen K (2016) Migraine as a predictor of mortality: the HUNT study. Cephalalgia 36(4):351357

12. Rambarat CA, Elgendy IY, Johnson BD et al (2017) Migraine headache and long-term cardiovascular outcomes: an extended follow-up of the Women's ischemia syndrome evaluation. Am J Med 130(6):738-743

13. Harnod T, Lin C-L, Kao C-H (2018) Survival outcome and mortality rate in patients with migraine: a population-based cohort study. J Headache Pain 19(1):57

14. Lee I-M, Cook NR, Gaziano JM et al (2005) Vitamin E in the primary prevention of cardiovascular disease and cancer: the Women's health study: a randomized controlled trial. JAMA 294(1):56-65

15. Ridker PM, Cook NR, Lee I-M et al (2005) A randomized trial of low-dose aspirin in the primary prevention of cardiovascular disease in women. $\mathrm{N}$ Engl J Med 352(13):1293-1304

16. Kurth T, Slomke MA, Kase CS et al (2005) Migraine, headache, and the risk of stroke in women: a prospective study. Neurology 64(6):1020-1026

17. Schürks M, Buring JE, Kurth T (2009) Agreement of self-reported migraine with ICHD-II criteria in the Women's health study. Cephalalgia 29(10):10861090

18. Cleeman JI, Grundy SM, Becker D, Clark L (2001) Expert Panel on Detection, Evaluation, and Treatment of High Blood Cholesterol in Adults. Executive Summary of The Third Report of The National Cholesterol Education Program (NCEP) Expert Panel on Detection, Evaluation, And Treatment of High Blood Cholesterol In Adults (Adult Treatment Panel III). JAMA 285(19): 2486-2497

19. Winter AC, Berger K, Buring JE, Kurth T (2012) Associations of socioeconomic status with migraine and non-migraine headache. Cephalalgia 32:159-170

20. Li Cl, Mathes RW, Bluhm EC et al (2010) Migraine history and breast cancer risk among postmenopausal women. J Clin Oncol 28(6):1005-1010

21. Kurth T, Schürks M, Logroscino G, Gaziano JM, Buring JE (2008) Migraine, vascular risk, and cardiovascular events in women: prospective cohort study. BMJ 337:a636

22. Lowry SJ, Malone KE, Cushing-Haugen KL, Li Cl (2014) The risk of breast cancer associated with specific patterns of migraine history. Cancer Causes Control 25(12):1707-1715

23. Mathes RW, Malone KE, Daling JR et al (2008) Migraine in postmenopausal women and the risk of invasive breast cancer. Cancer Epidemiol Biomark Prev 17(11):3116-3122

24. Winter AC, Rice MS, Fortner RT, Eliassen AH, Kurth T, Tamimi RM (2015) Migraine and breast cancer risk: a prospective cohort study and metaanalysis. J Natl Cancer Inst 107(1):381

25. Becker C, Brobert GP, Almqvist PM, Johansson S, Jick SS, Meier CR (2008) Migraine incidence, comorbidity and health resource utilization in the UK. Cephalalgia 28(1):57-64

26. Rice MS, Rist PM, Winter AC, Kurth T, Tworoger SS (2018) Migraine and invasive epithelial ovarian cancer risk in the nurses' health study II and the Women's health study. Int J Cancer 142(3):534-539

27. Tietjen GE, Herial NA, White L, Utley C, Kosmyna JM, Khuder SA (2009) Migraine and biomarkers of endothelial activation in young women. Stroke 40(9):2977-2982
28. Malik R, Freilinger T, Winsvold BS et al (2015) Shared genetic basis for migraine and ischemic stroke: a genome-wide analysis of common variants. Neurology 84(21):2132-2145

29. Winsvold BS, Nelson CP, Malik R et al (2015) Genetic analysis for a shared biological basis between migraine and coronary artery disease. Neurol Genet 1(1):e10

30. Tietjen GE, Khubchandani J (2015) Vascular biomarkers in migraine. Cephalalgia 35(2):95-117

31. Liman TG, Bachelier-Walenta K, Neeb L et al (2015) Circulating endothelial microparticles in female migraineurs with aura. Cephalalgia 35(2):88-94

32. Sacco S, Kurth T (2014) Migraine and the risk for stroke and cardiovascular disease. Curr Cardiol Rep 16(9):524

\section{Publisher's Note}

Springer Nature remains neutral with regard to jurisdictional claims in published maps and institutional affiliations.
Ready to submit your research? Choose BMC and benefit from:

- fast, convenient online submission

- thorough peer review by experienced researchers in your field

- rapid publication on acceptance

- support for research data, including large and complex data types

- gold Open Access which fosters wider collaboration and increased citations

- maximum visibility for your research: over $100 \mathrm{M}$ website views per year

At $\mathrm{BMC}$, research is always in progress.

Learn more biomedcentral.com/submissions 